\title{
HUMAN PERFORMANCE VARIATION ANALYSIS: A PROCESS FOR HUMAN PERFORMANCE PROBLEM SOLVING
}

\author{
Authors: \\ Anerie Rademeyer \\ Yvonne du Plessis ${ }^{1}$ \\ Charles H. Kepner ${ }^{1}$
}

\section{Affiliations:}

${ }^{1}$ Department of Human Resource Management,

University of Pretoria,

South Africa

\section{Correspondence to:}

Anerie Rademeyer

e-mail:

anerie@

switchedondevelopment.com

\section{Postal address:}

PO Box 524, Auckland Park, 2006, South Africa

\section{Keywords:}

root cause analysis; human performance assessment;

human performance

resolution; human

performance improvement

performance management

\section{Dates:}

Received: 05 Nov. 2008

Accepted: 06 Mar. 2009

Published: 28 May 2009

How to cite this article:

Rademeyer, A., Du

Plessis, Y., \& Kepner,

C.H. (2009). Human

performance variation

analysis: A process for

human performance

problem solving. $S A$

Journal of Human Resource

Management/SA Tydskrif vir

Menslikehulpbronbestuur,

7(1), Art. \#174, 9 pages. DOI:

10.4102/sajhrm.v7i1.174

This article is available

at:

http://www.sajhrm.co.za

(C) 2009. The Authors.

Licensee: OpenJournals

Publishing. This work

is licensed under the

Creative Commons

Attribution License.

\begin{abstract}
Problem-solving ability is a much sought-after trait in executives, especially if it includes the ability to solve human performance problems. This paper proposes a systematic root cause analysis process that effectively and consistently uncovers the root causes of human performance problems and controls the causes in a way that prevents the problems from recurring. Applying action research the study brings into being a Human Performance Variation Analysis (HPVA) process, which consists of three phases: (1) performance variation assessment, (2) performance variation analysis, and (3) performance variation resolution. The HPVA provides much-needed capability in solving human performance problems in organisations.
\end{abstract}

\section{INTRODUCTION}

According to a survey of 1000 executives conducted by Caliper Associates, reported in the Wall Street Journal by Hal Lancaster (Hoenig, 2002, p. 338), problem-solving ability is a much sought-after trait in executives, especially if it includes the ability to solve human performance problems. Human performance is an important aspect of any organisation's performance, but, unlike other areas of company performance, so far, the root cause of human performance or non-performance has not been assessed from a root cause analysis point of view.

The origins of root cause analysis can be traced to the broader field of total quality management, or TQM (Andersen \& Fagerhaug, 2006, p. 12). Root cause analysis has been defined as 'a structured investigation that aims to identify the true cause of a problem and the actions necessary to eliminate it' (Neal, Watson, Hicks, Porter \& Hill, 2004, p. 75). Root cause analysis originated in the field of engineering, and, during the last three decades, it has been applied in fields such as aerospace, transportation, nuclear power, chemical processing, pollution control, information technology, manufacturing and health care (Cheryl Gray Instructional Design, n.d.). It is evident from this list that the field of human resource management has not hitherto been an area in which root cause analysis has been applied.

The research objective of this study was to apply and test a root cause analysis process that would uncover the causes of human performance problems. The authors believe that human performance problems require the same detailed scrutiny and attention that problems in the fields mentioned above do.

According to Piskurich (2002, pp. 57-58) and Rothwell, Hohne and King (2000, pp. 67-71), the most common analysis tools used to examine human performance are brainstorming, cause-and-effect analysis (also known as the fishbone or Ishikawa diagram) and the five why's technique. On the basis of their extensive experience in the field of root cause analysis, the researchers recognise these techniques as robust and useful. However, these techniques do have a number of shortcomings and, as a result, are used with limited success in identifying the root causes of human performance problems. Firstly, they lack a precise, agreed-upon definition of the required or desired performance. Secondly, they lack a means of identifying what information is relevant. Thirdly, they cannot identify sources of relevant, needed information, or those that can best judge the degree to which the conclusion explains the variation. Fourthly, they do not give guidance as to the remedial or corrective action that should be taken, which leads to much uncertainty and a trial-and-error adaptation of the action. The result is often confusion, mistrust, resentment and an erosion of loyalty to management. What is needed is a logical and verifiable process that can establish a data point on the basis of which relevant information can be recognised and gathered and against which the conclusion can be evaluated to gain confirmed knowledge of the root cause of the human performance problem concerned. A process is also required to facilitate the sharing of information between the manager or supervisor and the performer of an action - they should become partners in formulating ideas and conclusions based on the facts and on their combined knowledge and experience.

The main aim of this paper is to report on a root cause analysis process that can assist managers and supervisors to uncover and solve the root causes of uncontrolled variations in human performance and thereby become effective problem solvers of human performance problems.

\section{Research approach}

\section{RESEARCH DESIGN}

A root cause analysis process was explored in human performance by means of a qualitative research approach, using action research. According to Hopkins (1993, cited in Gabel, 1995), the action research framework is the most appropriate method for recognising the existence of shortcomings, because it allows a researcher to adopt an initial stance with regard to the problem(s), formulate a plan, carry out an investigation, evaluate the outcomes and develop further strategies in an iterative fashion. According to McNiff and Whitehead (2006, p. 45), action research has two main purposes, namely first, to contribute to new practices and, second, to contribute to new theory. They argue that the 
main social purposes of action research include that it aims to improve workplace practices by improving learning, to promote the ongoing democratic evaluation of learning and practices, and to create good social order by influencing the education of social formations (McNiff \& Whitehead, 2006, p. 32). Action research is significant if the researcher can generate and test the theory in relation to his or her own learning, the learning of others in workplaces and social situations, and education regarding social formations (McNiff \& Whitehead, 2006, p. 233).

\section{Research strategy}

The strategy used in this study was to explore a root cause analysis process that was initially developed and to refine it for human performance variation analysis. The initial root cause analysis process was applied and modified repeatedly in the light of what was observed or of the feedback that was received from respondents. Therefore, the protocol followed in this study was iterative or cyclical and was aimed at developing a deeper understanding of the performance problem and the required solution. The strategy consisted of the following steps (MacIsaac, 1996, p. 2):

Realising a problem - realising that some kind of improvement or change was needed in the cause analysis approach that is currently used in performance management. Planning developing a better understanding of the problem and planning for the intervention. Action - carrying out the intervention. Feedback - collecting pertinent feedback during and about the intervention. Reflection and revision-using reflection to develop a new intervention from the body of previous knowledge, and carrying out a new intervention until a sufficient solution for the problem was achieved. The above steps occurred in more or less the same sequence throughout the study. The realisation of the problem led to planning and the planning was in turn embedded in the action, feedback, reflection and revision. The steps were repeated until a sufficient solution to the problem that was initially identified had been developed, namely the development of a root cause analysis process for uncontrolled variations in human performance.

\section{RESEARCH METHOD}

\section{Research setting}

The root cause analysis process was tested in two organisations - the first test was conducted on a voluntary basis with a group of students at a university in Italy that was founded in 1991 and offers undergraduate, graduate and executive programmes to local and international students; the second test was conducted with a consulting firm in South Africa that was founded in 1986 and specialises in the fields of root cause analysis, decision making, project management, innovation, and Six Sigma, which is a data-driven methodology for identifying and eliminating the causes of defects and variation in manufacturing and business processes. These two organisations were appropriate for this study because they either had experience in root cause analysis or worked with variations in human performance.

\section{Entrée and establishing researcher roles}

Access was negotiated and gained to the university through the university's associate director and the managing partner of CIMBA Business Advisement, who led the testing process and coached students during their applications. The researchers contacted and liaised directly with the consultants at the South African consulting firm, after permission was obtained from the managing director.

\section{Sampling}

A purposive convenience sampling technique was applied, as action research was involved and participants had to understand the process. The root cause analysis process was tested by 29 students who were doing their Master's degrees in Counselling Psychology at the chosen university. Five of the ten consultants at the consulting firm in South Africa also volunteered to test the root cause analysis process. These five respondents had between five months' and 25 years' experience in the root cause analysis field.

Although these sample sizes seem relatively small, the comments cited from Miles \& Huberman (1994, p. 27) and Jones (2002, p. 4) below confirm that appropriate sample size has less to do with the actual numbers of participants than with the quality and depth of information elicited through the research process. 'Qualitative researchers usually work with small samples of people, nested in their context and studied in-depth' (Miles \& Huberman, 1994, p. 27). According to Patton (1990, cited in Jones, 2002, p. 4), 'sample size depends on what you want to know, the purpose of the inquiry, what's at stake, what will be useful, what will have credibility, and what can be done with available time and resources'. Patton (1990, cited in Jones, 2002, p. 4) suggests that the researcher must establish a minimum sample size based on the number of participants needed to provide 'reasonable coverage of the phenomenon given the purpose of the study'.

\section{Data-collection methods}

The purpose of data gathering is to generate evidence to support researchers' claim to knowledge. Action research was chosen as the best research method for this study, because it is a cyclical, iterative process that is rigorous, responsive, flexible and can contribute to the refinement of a root cause analysis process, as undertaken in this study. When looking for data during action research, one looks for episodes of practice that will produce evidence of one's own learning, as well as the learning of others (McNiff \& Whitehead, 2006, p. 137). The study followed three iterative cycles of development and testing.

Cycle 1

An initial root cause analysis process (not reported here) was verified by a one-on-one consultation with the manager of a sales consultant who was not expanding the business through existing and new customers; a one-on-one consultation with the supervisor of a front-line employee who was tardy at doing certain jobs and following work procedures; and a case study of a repairman who was not following the company's sales lead programme. The lessons learned from this cycle were used to improve areas in the root cause analysis process that required further refinement for human performance root cause analysis.

Cycle 2

29 students who were doing their Master's degrees in Counselling Psychology at a university in Italy tested the root cause analysis process by applying the process to their own situations. The following are examples of the type of situations to which they applied the root cause analysis process: a performer who:

- is late and/or absent from meetings.

- ignores e-mails, calls and messages and has not met with the supervisor for three weeks.

- does not complete the test in the allocated time.

- does not consistently interact socially.

- does not attend classes.

- breaks the law by stealing.

The students received a worksheet and process questions as support materials. The worksheets were reviewed to identify information gaps. Based on these worksheets and feedback received from the managing partner of CIMBA Business Advisement, who led the session, further improvements were made to the root cause analysis process. 


\section{Cycle 3}

Five expert consultants in the root cause analysis field at a South African organisation volunteered to test the root cause analysis process by applying it to a case study. According to Emory and Cooper (1991, p. 143), 'a single, well-designed case study can provide a major challenge to a theory and provide a source of new hypotheses and constructs at the same time.' The case study that was used in this study was sourced from an international company that specialises in root cause analysis, decision making, project management and innovation. It describes a human performance problem that the organisation experienced, namely a high error rate on claims transactions due to incorrect data input by one of its employees.

The five expert consultants completed the case study application, individually and at their own pace, by following the process questions and completing the worksheet. They also completed a feedback guide after the application. The worksheets were reviewed for information gaps and incorrect information, while the feedback guides were reviewed for common themes that suggested further improvements. The results were used to make final changes to the root cause analysis process.

\section{Recording of data}

A root cause analysis worksheet and feedback guide was developed to record data during and after the application of the root cause analysis process. The purposes of obtaining feedback from participants were to:

- judge how well the root cause analysis process works.

- identify problem areas that required further improvement.

- evaluate the strengths and weaknesses of the root cause analysis process.

- determine the value of the root cause analysis process in practice.

- The overall aim of the feedback was to develop a better quality root cause analysis process.

Feedback from the university students was obtained in the following formats:

- Root cause analysis worksheets completed by the students who had applied the root cause analysis process to their own situations.

- Numerous telephonic discussions with the managing partner at CIMBA Business Advisement who championed this testing phase.

Feedback was obtained from the consultants at the South African consulting firm in the following formats:

- Root cause analysis worksheets and feedback guides completed by the consultants who had applied the root cause analysis process to the case study.

- Personal notes kept of informal discussions with the consultants to obtain supplementary information about their applications of the root cause analysis process. Open dialogue between the researcher and respondents played an important role during this phase of the study, with all five respondents contributing to the development of the best solution.

In qualitative research, a researcher's objectivity is of the utmost importance. According to Glesne and Peshkin (1992, cited in Thomas, 2003, p. 2), care must be taken to prevent the researcher from 'contaminating' the data through personal involvement with the research subjects. To avoid contamination of the data, the following guidelines were applied during the testing process:

- Being open to the ideas and views of the people to whom the root cause analysis process was applied.

- Trusting the root cause analysis process and not following a usual way of thinking and working.

- Not taking shortcuts, but rather putting energy and effort into the application.
Instead of referring to 'objectivity', Lincoln and Guba (1985, cited in Hoepfl, 1997, p. 60) prefer to talk about the 'confirmability' of the research. This refers to 'the degree to which the researcher can demonstrate the neutrality of the research interpretations' (Lincoln \& Guba, 1985, cited in Hoepfl, 1997, p. 60) by providing an audit trail. The following audit trail was kept from the above process applications to comply with the requirements of confirmability:

- raw data

- process notes

- personal notes

- the preliminary development information

- data analysis.

The purpose of data analysis is to produce evidence and to establish the trustworthiness of a claim. Generating evidence is a rigorous process that involves the following (McNiff \& Whitehead, 2006, p. 148):

- Making a claim to knowledge, by saying one knows something now that was not known before and adding it to the public body of knowledge

- Establishing criteria and standards of judgement

- Searching the data archive and selecting data

- Generating evidence.

The data gathered during this study was analysed in the following ways:

- Original worksheets were reviewed to identify information gaps and/or incorrect information. Through these analyses, potential problem areas in the root cause analysis process were identified.

- Respondents' feedback sheets were analysed for the following:

${ }^{\circ}$ Concepts, words or situations that described most of the feedback.

- Themes or trends that represented most of the feedback. Golden threads that ran through all the feedback.

This process helped make sense of the feedback and identified the areas in the root cause analysis process that needed further improvement.

\section{Strategies to ensure quality research}

A consideration of quality is fundamental to all research and is the responsibility of the researcher in ensuring research rigour. Lincoln and Guba (1985, cited in Shah \& Corley, 2006, p. 1829) explain that because qualitative research is 'based on a different set of ontological and epistemological assumptions' than quantitative research, the traditional notions of validity and reliability as applied in quantitative research should be replaced by an alternative set of criteria for qualitative research reflecting trustworthiness, namely credibility, transferability, dependability and confirmability. Table 1 outlines a set of specific actions a researcher can take to help meet each of these criteria.

The following actions were taken during the study to ensure the trustworthiness of the research:

- A sound research methodology was followed to ensure the advancement of knowledge

- The appropriate level of confidentiality was maintained throughout the research, by ensuring that the respondents and performers whose performance was evaluated remained anonymous

- Respondent involvement and participation were voluntarily and were encouraged at all stages of the research process

- Permission was obtained from the organisations who participated in the research to allow their students/ employees to participate in the research

- Respondents were allowed to do their applications independently and to complete their own worksheets 
- Debriefings were conducted with champions/respondents after process applications

- Records and notes were kept of debriefings and discussions with champions/respondents

- A project archive was kept of all original worksheets and feedback guides to substantiate the research findings.

\section{Reporting}

Reporting is an essential element in action research. While most research findings are never reported directly to those from whom the data were collected, feedback is essential in action research if management and other organisational members are to be persuaded of the need for action (Wilson, 2000).

The following methods can be applied in reporting action research (Brown, 1999):

- Involving others, such as participants, friends or collaborative friends, in the research

- $\quad$ Sharing ideas and research experiences with visitors

- Oral reports and seminar-style discussions

- Presenting information in graphic form

- Audiovisual presentations

- Exhibiting findings

- Acting on the results

- Disseminating findings through computer networks

- Publishing written reports.

The results of this study are reported with the aim of sharing the research knowledge and of developing managers and supervisors in the field of human performance management. It was therefore decided that the most effective way to report the outcomes of this study would be to use the information to develop a root cause analysis training programme that focuses on variations in human performance.

TABLE 1

Methods to ensure the quality of qualitative research (Shah \& Corley, 2006, p. 1830)

\begin{tabular}{|c|c|c|}
\hline $\begin{array}{c}\text { TRADITIONAL } \\
\text { CRITERIA - } \\
\text { QUANTITATIVE }\end{array}$ & $\begin{array}{c}\text { QUALITATIVE } \\
\text { CRITERIA - } \\
\text { TRUSTWORTHINESS }\end{array}$ & $\begin{array}{c}\text { METHODS OF } \\
\text { MEETING } \\
\text { TRUSTWORTHINESS }\end{array}$ \\
\hline Internal validity & Credibility & $\begin{array}{l}\text { Extended engagement in the field } \\
\text { Triangulation of data types } \\
\text { Peer debriefing } \\
\text { Member checks }\end{array}$ \\
\hline External validity & Transferability & $\begin{array}{l}\text { Detailed (thick) description of: } \\
\text { - Concepts and categories in the } \\
\text { grounded theory } \\
\text { - Structures and processes related } \\
\text { to process revealed in the data }\end{array}$ \\
\hline Reliability & Dependability & $\begin{array}{l}\text { Purposive and theoretical sampling } \\
\text { Informants' confidentiality protected } \\
\text { Inquiry audit of data-collection, } \\
\text { management and analysis processes }\end{array}$ \\
\hline Objectivity & Confirmability & $\begin{array}{l}\text { Explicit separation of first order and } \\
\text { second order findings } \\
\text { Meticulous data management and } \\
\text { recording: } \\
\text { - Verbatim transcriptions of } \\
\text { interviews } \\
\text { - Careful notes of observations } \\
\text { - Clear notes on theoretical and } \\
\text { methodological decisions } \\
\text { - Accurate records of contacts and } \\
\text { interviews }\end{array}$ \\
\hline
\end{tabular}

\section{FINDINGS}

The Human Performance Variation Analysis (HPVA) process was tested in real-life situations, as well as against a case study. Data analysis of the process worksheets and feedback guides indicated the following:

- The HPVA process, as developed in this study, can successfully reveal the causes of poor performance

- If different people apply the process using the same set of data, they will reach the same conclusion

- The HPVA process can assist managers in analysing the human performance situation effectively before identifying possible solutions, thereby addressing the human performance problem in the most effective way

The HPVA process provides a map for working through a human performance problem. It helps an analyst to gather all the relevant information that will lead to the discovery of the root cause of a human performance problem, and ensures that all the relevant information is considered before reaching conclusions and taking corrective action. The HPVA process should, however, only be applied if the situation meets the following criteria:

- The performance, job or situation under investigation is critical.

- It is likely that the human performance problem will worsen if no action is taken.

- The level of performance that the performer is expected to achieve is practical, achievable and realistic. If it is not, the standard needs to be revisited first.

- The supervisor or manager and performer share the same understanding of the expected or required level of performance (the standard).

- The cause for the human performance problem is unknown and is difficult to find.

- The costs and benefits of solving the human performance problem outweigh the costs and benefits of not addressing it.

If the above criteria are met, then there is a strong likelihood that the organisation is facing a human performance problem that requires deeper analysis. In such a case, the HPVA process can be applied to reveal the cause(s) of the performance problem(s). Figure 1 presents a graphic depiction of the phases and steps in the HPVA process. The process is discussed in detail below.

\section{Part 1: Performance variation assessment}

Part 1 of the HPVA process identifies, and clearly and specifically defines and describes, firstly, the person whose performance is to be analysed and, secondly, the performance problem that needs to be analysed and solved. This ensures that everyone has a shared understanding of the situation and that the analysis is focused.

Part 1 of the HPVA process consists of five steps, as depicted in Figure 1, and discussed below.

Step 1: Identify the performer

Step 1 of the process is to identify the specific person, or persons, whose performance is causing concern (What is the person's name?). Different human performance problems have different causes and, therefore, the analyst should ideally focus on a specific, single performer. If one wants to analyse the performance of a group, it is important to check that all the members of the group are performing exactly the same job or task and display exactly the same performance problem.

\section{Step 2: Describe the performance requirement}

The performance requirement represents the performance standard and correct behaviour, as well as the performance goals and expectations regarding the performance output. The performance requirement provides a performance baseline or reference point. In this step, the expected or required level of performance should be written down. 


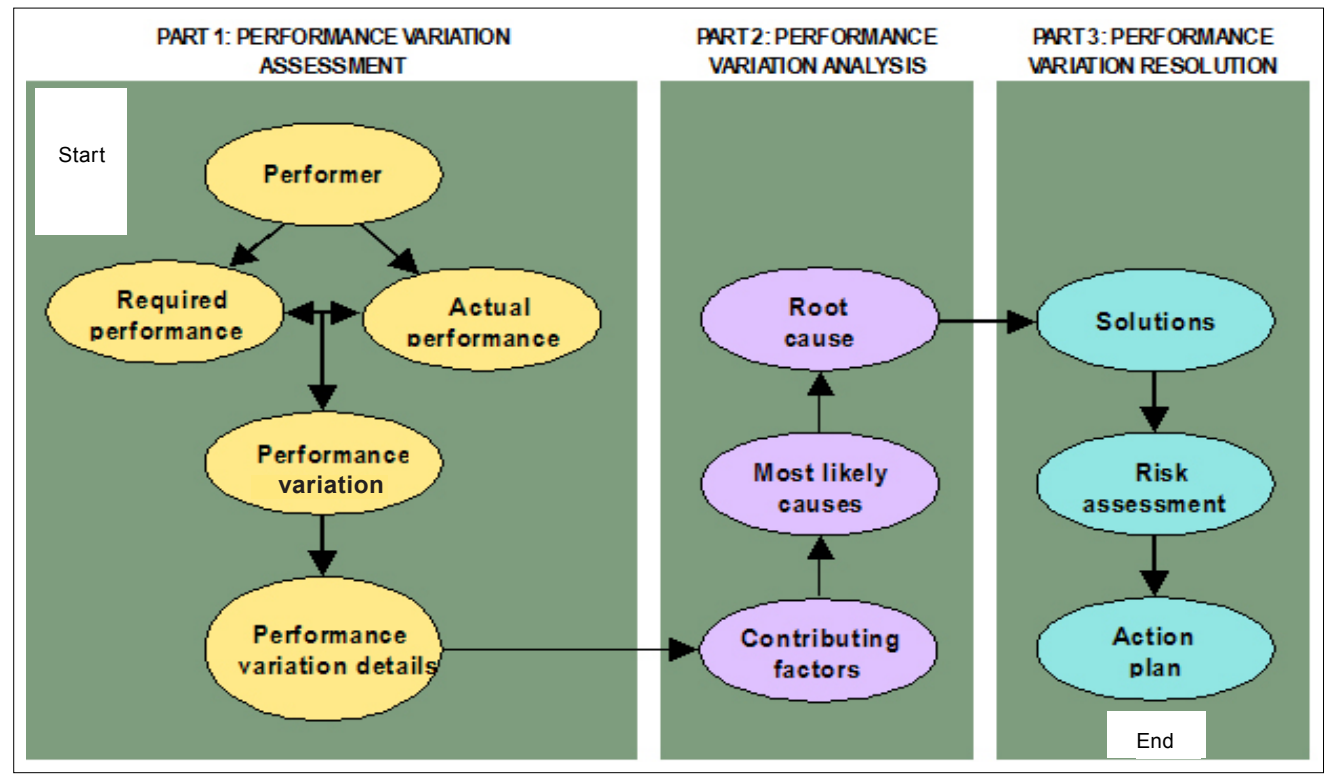

FIGURE 1

The Human Performance Variation Analysis (HPVA) process and steps (authors' own)

Step 3: Describe the actual performance

In this step, the actual performance must be described in specific detail (Exactly what does the performer currently do, or not do? How does the performer perform the job or task?). The purpose of this step is to gain more knowledge about the specific problem situation. The most valid source of information in Step 3 is to observe the actual performance. What has been observed must then be put into words as accurately as possible.

\section{Step 4: Describe the performance variation}

To determine the performance variation, one needs to compare the authenticated performance requirement to the performer's actual performance and describe the human performance problem in specific terms. The performance problem is the discrepancy between the desired performance and what actually happens. If the discrepancy is undesirable for the specific job or performer, then the situation calls for further action.

The analysis of the performance problem should not focus on a symptom of the problem, but must describe the real issue at hand - the problem that lies behind the symptom - in specific terms. A specific problem description that will sharpen the analysis should meet the following criteria (Ammerman, 1997, pp. 10-11):

- It focuses on the gap between what is and what should be

- It states the effect - what is wrong (not why it is wrong)

- It is measurable - for example, how often, how much, when - and avoids references to broad and ambiguous categories such as 'morale', 'productivity', and 'communication'

- It is stated in a positive manner and describes the painful effects of the problem

- It avoids 'lack of' and 'no' statements, as they imply solutions

- It highlights the significance of effects, and may state areas of discomfort, hurt or annoyance, or how people are affected.

\section{Step 5: Describe the performance variation details}

If one has no information about the performance problem, this could lead to a situation where facts are twisted to suit theories, instead of theories generated to suit the facts. The purpose of this step is the following:

- To ensure proper data collection about the human performance problem.

- To make the problem details visible to everyone concerned.
- To ensure that there are no misunderstandings, but that there is a shared understanding of the problem situation instead.

This step focuses on facts about the human performance problem, stated as straightforwardly and as objectively as possible. The analyst records what he or she sees. The problem description must be as free of error and uncertainty as possible. A good starting point is to determine what one knows for sure, what one believes to be true, and what one does not know. Consulting the right people during this step helps to ensure that validated, factual information is recorded. The best sources of information are people who have first-hand knowledge about and experience of the specific job that is being analysed. When one approaches other stakeholders or sources of information, the quality of the questions will determine the quality of the answers. Therefore, one should keep questions to the various stakeholders sharp and concise to ensure that their answers will add worthwhile information to the analysis.

To give an exact description of the problem situation, the analyst needs to gather information by asking a series of specific questions. Questions are the key to identifying and describing the details that will lead the analyst to the cause of the human performance problem. In this step, questions relating to the following dimensions are asked:

- The performer, by name, whose performance is causing concern

- The job or task in which the undesired performance or behaviour has been noticed

- The specific performance or behaviour that does not meet the expectation

- Thegeographiclocation in which the undesired performance or behaviour has been noted or reported

- When in clock or calendar time the performance problem occurred for the first time - knowing the time will help establish the relationship between the performance problem and other occurrences

- The times or frequencies at which the performance problem is noticed or reported.

The following types of information are recorded in an is-is not matrix for each of the above dimensions:

- Information about what the human performance problem is: The information recorded must be factual. If the is information cannot be recorded for any of the above 
dimensions, it means that the details about the performance problem are incomplete. In this instance, the analys needs to reach out to new sources of information that may potentially have the information he or she is still seeking.

- Information about what the human performance problem is not: This type of information indicates the boundaries or limits of the performance problem. These boundaries separate what the human performance problem is and what lies outside and is not part of the problem.

The information gathered during this step in the HPVA process will serve as a screening tool later in the analysis to test possible causes against. Testing possible causes on paper is much cheaper than verifying each possible cause in practice.

\section{Part 2: Human Performance Variation Analysis}

Part 2 of the HPVA process has been designed to be completed jointly by the manager or supervisor and the performer. The aim is to get the most accurate information about why the human performance problem exists. It is difficult to solve a problem when different people all have a different understanding of the problem and its causes. It should be borne in mind that the person performing the job or task is most likely to know what is causing the performance problem. Applying the HPVA process jointly, firstly, helps set a collaborative process in motion between the performer and the manager or supervisor and, secondly, clarifies each person's role in addressing the performance problem.

The ultimate purpose of Part 2 of the HPVA process is to identify the root cause of the human performance problem. This part of the HPVA process consists of three steps, as depicted in Figure 1 , and as discussed below.

\section{Step 1: Identify contributing factors}

The factors that affect human performance are numerous and diverse. Therefore, the aim of the first step of this phase is to list everything that is special or unique of the is when compared to the is not and to record all changes that have taken place. All the unique factors that were either present (what is) or absent (what is not), in other words what is missing or ineffective and could have caused or contributed to the human performance problem, must be recorded. This step focuses on the following categories of human performance factors:

- Factors that pertain to the performer, for example his or her skills, competency, capacity, motives and suitability for the job or task

- Factors that pertain to the job or task, for example the job design, the complexity of the job, workload, workflow, information, policies, procedures and supervision

- Factors that pertain to the performance itself, for example the job expectations, consequences and feedback

- Factors that pertain to the geographic location where the job or task is performed, for example the physical working conditions, resources and job aids

- Factors that pertain to the date and time at which the performance problem occurred for the first time

- Factors that pertain to the times and frequency at which the performance problem is noticed.

Both the experience and the intuition of the analyst are useful tools in this step of the HPVA process. It is important that one keeps digging into the problem's details for as long as new information or information that has previously been overlooked is discovered. In some instances, it might even be necessary to involve or seek out ideas and additional information from other people who have special skills and knowledge and to incorporate this information into the analysis. One of the most valuable sources of information is the experience and opinion of those who are the closest to the scene of action. One needs to use everything one knows to understand what could have caused the human performance problem. As an analyst, one knows that one has reached the point of saturation when the same information is repeated and no new information about the performance problem surfaces.

Step 2: Crystallise the most likely causes

Usually, different factors come together to constitute a cause. Once all the factors that might have caused or contributed to the human performance problem have been identified, the analyst can start to hypothesise possible causes for the performance problem. This is done in the following ways:

- Evaluating all the factors that were listed and identifying the ones that have failed or were missing. This involves describing how each of the failing or missing factors was ineffective and why it was ineffective.

- Describing how each factor, or a combination of factors, could have caused the performance problem, or could have prevented the performer from performing to standard.

- Asking 'How could the performance problem have occurred?' Asking 'how could' instead of 'why' at this stage in the HPVA process ensures that possible causes are identified that go beyond the ones that are merely the most likely ones. According to Paradies and Unger (2000, p. 36), humans have a negative emotional response to the question 'why' if it is asked during a root cause analysis process.

The above process will result in a list of reasons that can be used separately, or as combinations, to phrase specific statements or hypotheses that explain why the performance problem occurred.

\section{Step 3: Identify the root cause}

This step in the HPVA process aims to achieve the following:

- It eliminates apparent and presumptive cause statements that the performance problem details do not support

- It selects the most plausible cause that requires further verification

- It identifies the root cause of the human performance problem that requires corrective action.

Step 3 in Part 2 of the HPVA process requires the use of information and reasoning skills based on logic to support or eliminate possible causes. There are three stages to pass through before a possible cause can be confirmed to be the root cause of the performance problem:

- Proving the cause on paper:

Any possible cause is merely speculation until it has been confirmed or proved. The identification of a possible cause needs to be based on fact. In the HPVA process, each possible cause statement should be checked against what is known about the performance problem, as recorded in the is-is not matrix. If a cause statement is true for the specific performance problem, then it must, firstly, account for all the performance problem details ('this explains that') for both the problem (what is) and comparable (is not) situations and, secondly, make logical and practical sense. In other words, a cause statement will be proven if it explains all the performance problem details in the is-is not matrix, without exception and without many assumptions.

- Confirming the cause in real life:

A likely explanation is not guaranteed to identify the precise cause of the human performance problem. The precise cause can only be determined when evidence or hard data has been collected that confirms the likely cause in real life. Therefore, the aim of this step is to deliberately seek evidence to prove that the identified cause for the human performance problem is the correct one. This is done by conducting an independent experiment in which the cause must produce exactly the same human performance problem that is causing concern or by finding independent evidence that confirms the link between the cause and the effect.

- Determining the root cause:

Knowing what has happened and being able to prove and confirm it is essential in preventing the cause from 
recurring. Moreover, knowing why it has happened is a vital part of managing human performance in future. The basic principle of cause and effect is that every action has at least one conditional cause that existed in time before the action set in motion the chain of events that led to the undesirable effect. Therefore, the aim of this step is to identify the conditional cause(s) that existed in time when the performance problem occurred. The conditional cause(s) is the true root cause(s) for the human performance problem. Therefore, the only way to prevent recurrence of the same performance problem due to the same root cause(s) is to address the conditional cause(s). The following criteria help to establish whether or not the identified cause is the root cause (Ammerman, 1997, pp. 68-69):

- The human performance problem would not have occurred had the cause not been present.

- The human performance problem will not recur due to the same causal factor if the cause is corrected or eliminated.

- Correction or elimination of the cause will prevent recurrence of similar conditions.

\section{Part 3: Performance variation resolution}

Like Part 2, Part 3 of the HPVA process has been designed to be completed jointly by the manager or supervisor and the performer. Involving the performer in this part of the process is important, because he or she is the person who will be responsible for implementing the solution and making it successful. The advantage of making the performer responsible is that he or she knows the situation best, that he or she knows what the solution entails, and that it makes the person who will work with the solution responsible for its implementation. Management would, however, need to take responsibility for any corrective actions that are related to management issues.

The aim of Part 3 of the HPVA process is to develop an action plan that would rectify the human performance problem and set things right again. This part of the HPVA process consists of three steps, as depicted in Figure 1, and discussed below.

\section{Step 1: Select the best workable solution}

Step 1 in Part 3 of the HPVA process identifies and lists all corrective actions required to address the root cause of the problem to prevent the human performance problem from recurring, or to greatly reduce the probability that the human performance problem will recur due to the same root cause. The individual and/or collective actions that need to be taken should be listed. Corrective actions are the countermeasures taken against the root or contributing causes (Ammerman, 1997, p. 71).

The goal is, firstly, to draw on the experience, knowledge and judgement of the best information sources to create a pool of ideas and, secondly, to select the best actions from the possibilities available that would correct the causes of the specific human performance problem under review. The following requirements need to be considered when selecting actions:

- The action must add value - it must prevent the recurrence of the human performance problem by eliminating or reducing the root cause.

- It must be feasible to implement the action with current or readily obtainable resources, considering the time, costs and other resources that the action will require for successful implementation and continued effectiveness. Taking the action must be cheaper than leaving the human performance problem unresolved.

- It must be within the capability of the organisation to implement the action and the action must be compatible with the organisation's other commitments and policies.

- The action must be acceptable to others in the organisation and must be free, or relatively free, from negative effects on other areas and people.
Finally, when selecting a solution, the analyst must put himor herself in the performer's position and ask him- or herself whether the proposed actions steps are realistic in view of the performance situation.

\section{Step 2: Conduct a risk assessment}

The initial action plan that contains the corrective actions needs to go through a process of inspection and improvement before it can be considered adequate. The aim of Step 2 is to ensure that the action plan is practical for its implementation, by anticipating and avoiding or minimising any adverse effects, risks or negative consequences that could arise as a result of the corrective actions. The following sequence is followed in this step of the HPVA process:

- Investigate the mechanics of the plan, as well as other areas and activities in the organisation and the external environment, and anticipate any potential risks as a result of the corrective actions. List these risks.

- Identify and list ways to avoid or prevent these risks.

- Investigate the mechanics of the plan, as well as other areas and activities in the organisation and the external environment, and anticipate potential negative side effects as a result of the corrective actions.

- Identify ways to minimise these potential negative side effects if they do occur.

- Reach agreement on the most effective and viable preventive and contingent actions.

- Update the action plan by incorporating the selected preventive and contingent actions.

\section{Step 3: Finalise the action plan}

The final action plan must be practical, workable and realistic. It must include the following:

- The name of the person responsible for each action step.

- The name of the person responsible for monitoring the plan and giving feedback.

- A list of cost-effective actions that will correct the conditional causes and will prevent the human performance problem from recurring, or greatly reduce the probability that the human performance problem will recur due to the same root cause.

- A list of cost-effective actions that will avoid or minimise any adverse effects, risks or negative consequences that could arise as a result of the corrective actions.

- The sequence of events that must be carried out.

- Information on when each action needs to be implemented.

\section{DISCUSSION}

This study enabled the development of a root cause analysis process that can assist managers and supervisors with uncovering and solving the root causes of uncontrolled variations in human performance and thereby become effective problem solvers of human performance problems. This process is involved as it entails multiple steps that have to be followed. The HPVA promises many benefits from both a situational and a process point of view. However, the study also had some limitations, which are also discussed in more detail below.

\section{Benefits}

The HPVA process can be applied in any of three potential situations. The first is a friendly, cooperative and collaborative situation ('Let's sit down together and resolve this problem'). The second is a neutral situation ('One way or another, I have to solve this problem to keep things going'). The third is a hostile situation ('Somebody messed up and heads are about to roll'). In the latter case, it can be expected that stakeholder involvement will be defensive with excuses and different kinds of evasive tactics. In this instance, using the HPVA process to prove the cause objectively is vital. 
Applying the HPVA process offers the following benefits:

- It provides a systematic map to uncover and solve uncontrolled variations in human performance

- It provides a tool that helps determine what information is relevant, how to make sense of all the information available to the analyst and how to organise the information in a sensible manner

- It does not solve human performance problems by blame fixing or finger pointing, but by following a collaborative, cooperative process

- It gives the performer a vehicle through which he or she can actively participate in his or her performance discussion in an open and honest way

- It focuses the people involved on information gathering and cause identification, so that they can avoid the trap of being too solution-oriented

- It provides a tool that creates a shared understanding and a common reality based on all the perspectives of the human performance problem

- It brings different people from different levels and/or areas together to discuss human performance problems, to learn, to create a factual basis and to make progress in analysing a human performance problem

- It provides a testing base against which possible causes can be evaluated, to confirm which one is the root cause.

- It provides a tool to develop an action plan that would solve the root cause and prevent the source(s) of the problem from recurring

- It provides a tool to avoid any negative consequences due to the corrective action(s) taken

- It can empower managers and supervisors and increase their confidence in dealing with human performance problems

- It provides a tool with which human performance management can be standardised throughout the organisation.

\section{Limitations}

As much as possible was done during the study to identify potential limitations and to do whatever was possible to compensate for them. The study did, however, suffer from the following limitations:

- The HPVA process was tested by 29 Master's degree students, five expert consultants and two consultation sessions with clients. Although the process was tested using both real-life situations and case studies, it should be applied to many more situations before it can be regarded as truly reliable. Testing the process in as many real-life situations as possible will provide further lessons faster than any other method.

- While developing the HPVA process, the researchers' own experience in root cause analysis was brought to bear, including knowledge of some of the weaknesses of many of the existing problem-solving techniques. This might, however, raise a question of objectivity towards certain root cause analysis tools and techniques. However, the rationale for including the is-is not matrix in the HPVA process was the fact that it is one of the few methods available to establish an objective data point that indicates the relevant information needed and against which the conclusions can be evaluated.

- In all instances, convenience sampling was used. When selecting the students, the researchers were looking for a group of people who would all have real-life situations to apply the HPVA process to. When selecting the group of consultants, the researchers were looking for people who have root cause analysis experience. In both instances, the aim was also to protect the confidentiality and uniqueness of the HPVA process. Because people were used who were conveniently available to test the process, this might affect the degree of generalisability of the HPVA process.
- When the group of 29 Master's degree students tested the HPVA process, a managing partner at CIMBA Business Advisement srl. (Società a Responsabilità Limitata) led the session and coached the students during their applications. Although he is a highly skilled and experienced consultant and root cause analysis facilitator, the researchers did not have direct access to the students. As a result, some information might have gone missing in the feedback.

\section{Contributions}

The study adds value to the human resource management body of knowledge as well as practical applications in a number of ways:

- The research has provided managers and supervisors with a tool to uncover the root causes of uncontrolled variations in human performance effectively and consistently.

- The study has provided a root cause analysis tool that will, first, allow managers and supervisors and performers to formulate ideas and conclusions based not only on the facts, but also on their knowledge and experience (the process will lead them to apply their own thinking to find the cause(s) of problems and the best solution), and, second, bring different people from different levels and/or areas together to discuss human performance problems and create a shared understanding and common reality based on their different perspectives of the performance problem (performers will become partners in sharing information, finding the cause and developing the best solution).

- The study has provided a root cause analysis tool that can be used to identify measures to solve the root cause, prevent it from recurring, and sustain the new, improved level of performance.

- Technical experts who have advanced to a managerial or supervisory level no longer need to fear or steer clear of addressing human performance problems. The study has provided them with a human performance management tool that has the same structure as the cause analysis techniques they apply to technical, machine-related problems.

- The study provides organisations with a root cause analysis tool with which human performance management can be standardised throughout the organisation.

\section{Recommendations}

According to De Jager (2002, p. 14), action research could generate more questions than answers. Also, the development of a root cause analysis process such as the HPVA process evolves from continuous testing and refinement. Therefore, this study should not be regarded as the end of the road, but merely as the start of a lifelong journey.

The following may be regarded as further research opportunities:

- Research on the degree of success the HPVA process would have as a performance improvement tool, by focusing on and solving causes of controlled variations in human performance

- Research on managers' and supervisors' and performers trust in the HPVA process as a fair and reliable root cause analysis tool

- Research on the success rate of the HPVA process - the number of human performance problems solved the first time round

- A scientific measurement of the benefits reaped from applying the HPVA process

- Research to determine in which dimension(s) of the HPVA process - the performer, job or task, geographic location or time - most of the root causes of performance variations fall

- Research on the extent to which the HPVA process adds credibility in respect of fairness and increases loyalty and commitment to both the manager and company 
- Research to determine whether the HPVA process would enhance positive future collaboration between the manager/supervisor and the performer

- Research to determine whether the HPVA process with its openness and inclusion of broader sources of information would create trust and better working relationships between the manager/supervisor and the performer

- Research to determine whether the HPVA process would boost the performer's morale and motivation and enhance cooperation.

\section{Conclusion}

People do not purposefully want to attract negative attention, or arrive at work with the intention of performing poorly. The reality, however, is that people are human and make mistakes. Therefore, performance problems are likely to occur.

With straightforward, common human performance problems - for example, issuing the wrong application form to customers - it is common sense to try a series of quick and tested solutions starting with the most simple and the cheapest before moving on to those that take longer and cost more. However, when human performance problems of greater complexity occur - for example, a sudden increase in report mistakes - it may not be as simple or easy as applying a quick fix solution. In fact, the quick fix may do more harm than good. In these instances, a systematic process - such as the HPVA process - is needed to analyse the human performance problem. Only once the root cause has been identified can the most appropriate solution to the problem be developed.

According to Kepner and Iikubo (1996, p. 200), the problems people face today are so complex that no one person can be sure of having all the answers. Facing a problem requires us to find out more, ask the advice of others and gather suggestions. The challenge is to think deeper and further ahead. According to Hoenig (2002, p. 338), 'improved problem-solving capability is the ultimate competitive advantage, and the best organisations are increasing the sophistication with which they systematise their problem-solving processes.'

If organisations want to solve human performance problems, the manager or supervisor and performer need to pool their best knowledge and ideas to find the cause and develop solutions to such performance problems. The HPVA root cause analysis tool can facilitate the sharing of information between the manager or supervisor and performer and will make the analysis of the human performance problem more collaborative. It offers an advance in the management of human performance and provides a sought-after capability for problem solving, namely the ability to solve human performance problems.

\section{REFERENCES}

Ammerman, M. (1997). The root cause analysis handbook: A simplified approach to identifying, correcting and reporting workplace errors. New York: Productivity Press.

Andersen, B., \& Fagerhaug, T. (2006). Root cause analysis: Simplified tools and techniques. Milwaukee: ASQ Quality Press.

Brown, M.E. (1999). Action research. Retrieved November 20, 2008, from http://www.southernct.edu/ brownm/act7. html

Cheryl Gray Instructional Design. (n.d.). A brief history of root cause analysis. Retrieved June 5, 2008, from http://www. cherylgray.com/RCA/history.html

De Jager, A. (2002). An integrated and holistic approach to assessment in outcome-based learning in South Africa. Unpublished doctoral thesis, University of Pretoria, Pretoria, South Africa. Retrieved May 15, 2008, from http://hagar.up.ac.za/ catts/learner/de_jager_annette/phd/table_of_content.htm

Emory, C.W., \& Cooper, D.R. (1991). Business research methods. Homewood: Richard D. Irwin.
Gabel, D. (1995). An introduction to action research. Retrieved July 27, 2006, from http://physicsed.buffalostate.edu/danowner/ actionrsch.html

Hoenig, C. (2002). Developing exceptional problem-solving skills. In J. Glasspool (Ed.), Business. The ultimate resource. London: Bloomsbury.

Hoepfl, M.C. (1997). Choosing qualitative research: A primer for technology education researchers. Journal of Technology Education, 9(1), 47-63.

Jones, S.R. (2002). (Re)writing the word: Methodological strategies and issues in qualitative research. Journal of College Student Development, July/August, 1-12. Retrieved April 1, 2008, from http://findarticles.com/p/articles/mi_qa3752/ is_200207/ai_n9121404

Kepner, C.H., \& Iikubo, H. (1996) Managing beyond the ordinary. New York: AMACOM.

MacIsaac, D. (1996). An introduction to action research. Retrieved March 11, 2008, from http://physcised.buffalostate.edu/ danowner/actionrsch.html

McNiff, J., \& Whitehead, J. (2006). All you need to know about action research. London: Sage.

Miles, M.B., \& Huberman, A.M. (1994). Qualitative data analysis. Thousand Oaks: Sage.

Neal, L.A., Watson, D., Hicks, T., Porter, M., \& Hill, D. (2004). Root cause analysis applied to the investigation of serious untoward incidents in mental health services. Psychiatric Bulletin, 28, 75-77.

Paradies, M., \& Unger, L. (2000). TapRoot - the system for root cause analysis, problem investigation, and proactive improvement. Knoxville: System Improvements.

Piskurich, G.M. (2002). HPI essentials. Alexandria, VA: American Society for Training and Development.

Rothwell, W.J., Hohne, C.K., \& King, S.B. (2000). Human performance improvement. Houston: Gulf.

Shah, S.K., \& Corley, K.G. (2006). Building better theory by bridging the quantitative-qualitative divide. Journal of Management Studies, 43(8), 1821-1835.

Thomas, R.M. (2003). Blending qualitative and quantitative research methods in theses and dissertations. Thousand Oaks: Corwin.

Wilson, T.D. (2000). Recent trends in user studies: Action research and qualitative methods. Information Research, 5(3). Retrieved November 20, 2008, from http://informationr. net/ir/5-3/paper76.html 